International Journal of Maternal and Child Health and AIDS (2020), Volume 9, Issue I, 42-52

\begin{tabular}{ll}
\hline & INTERNATIONAL JOURNAL of \\
& MATERNAL and CHILD HEALTH and AIDS \\
& ISSN 216I-864X (Online) \\
& ISSN 216I-8674 (Print) \\
& DOI: 10.21 I 06 /ijma.323 \\
\hline
\end{tabular}

ORIGINALARTICLE

\title{
Association between Intimate Partner Violence, Knowledge and Use of Contraception in Africa: Comparative Analysis across Five African Regions
}

\author{
Rafeek A.Yusuf, MBBS, MPH, MS; ${ }^{\otimes}$ Deepa Dongarwar, MS; ${ }^{2}$ Zenab I.Yusuf, MBBS, MPH; ${ }^{3}$ \\ Hamisu M. Salihu, MD, $\mathrm{PhD}^{4}$ \\ 'Department of Management, Policy, and Community Health, University of Texas Health Science Center at Houston, School of Public Health, Houston, \\ Texas, USA; ${ }^{2}$ Center of Excellence in Health Equity, Training and Research, Baylor College of Medicine, Houston, Texas, USA; ${ }^{3}$ Menninger Department of \\ Psychiatry and Behavioral Sciences, Baylor College of Medicine, Houston, Texas, USA; Houston VA Health Services Research and Development Service \\ Center for Innovations in Quality, Effectiveness and Safety, Michael E. DeBakey VA Medical Center, Houston, Texas; and VA South Central Mental IIIness \\ Research, Education and Clinical Center, Houston, Texas, USA; ${ }^{4}$ FCM-Adminstartion Research, Baylor College of Medicine, Houston, TX, USA; Depart- \\ ment of Environmental and Occupational Health, University of South Florida, College of Public Health Tampa, Florida, USA; Department of Epidemiol- \\ ogy and Biostatistics, University of South Florida, College of Public Health Tampa, Florida, USA; and Center of Excellence in Health Equity, Training and \\ Research, Baylor College of Medicine, Houston, Texas, USA \\ Corresponding author email: rafeek.a.yusuf@uth.tmc.edu
}

\section{ABSTRACT}

Background Or Objectives: Intimate partner violence (IPV) against women is common globally, and is associated with several adverse consequences. This study provides a comparative analysis of potential regional differences in the association between IPV and knowledge and use of contraceptives within Africa.

Methods: A multi-country cross-sectional study was conducted using data on women of reproductive age 15-49 years from the Demographic and Health Surveys covering five African regions. Exposure and outcome variables were IPV and reproductive literacy (comprising modern contraception knowledge and contraception usage) respectively. We used survey log-binomial regression models to generate prevalence ratios that estimated the association between IPV versus knowledge and usage of modern contraception.

Results: Overall IPV prevalence in Africa was $30.8 \%$ with notable regional differences. Demographic, socioeconomic, and reproductive history markers of IPV were more pronounced in younger women, rural residents, women of low socioeconomic status and those with copious knowledge but poor usage of modern contraception. The level of knowledge of contraception was $84 \%$ greater among African women who were victims of IPV compared to their counterparts who were not victims of IPV $(P<0.000 \mathrm{I})$. IPV was not associated with actual usage of modern contraception $(p=0.2 \mathrm{I})$.

Conclusion And Global Health Implications: IPV against women in Africa may incentivize knowledge seeking of modern contraception as protective mechanisms. Regional variations notwithstanding, understanding the existing and new characteristics predictive of IPV may inform policy development, resource allocation and prevention of IPV globally.

Key words: Violence -Women - Contraception; $\bullet$ Knowledge • Usage • Africa • Intimate partner violence • Demographic and health surveys $•$ Benin $\bullet$ Burundi $\bullet$ Egypt $\bullet$ Kenya $\bullet$ South Africa

Copyright (C) 2020 Yusuf et al. Published by Global Health and Education Projects, Inc. This is an open-access article distributed under the terms of the Creative Commons Attribution License CC BY 4.0. 


\section{Introduction}

Intimate partner violence (IPV) is any intimate relationship-based behavior leading to physical, emotional or sexual abuse of individuals involved in the relationship.' IPV can affect either women or men in heterosexual or same-sex partner relationships. ${ }^{2}$ However, IPV is more commonly perpetrated against females by current or ex-male partners. ${ }^{3,4}$ IPV is one of the commonest forms of abuse affecting women globally. ${ }^{3,4}$ It results in adverse physical, mental, sexual and reproductive, psychological, financial, and other consequences including death for women experiencing such violence. ${ }^{1-5}$

\section{I. Background of the Study}

Globally, $13 \%$ to $61 \%$ of adult women have experienced physical IPV, ${ }^{3} 20 \%$ to $75 \%$ experienced emotional IPV, ${ }^{5}$ and $6 \%$ to $59 \%$ experienced sexual IPV. ${ }^{6}$ Lifetime prevalence of women experiencing either physical, sexual, or both physical and sexual IPV was I5\% to $75 \%$ between 2000 and 2003 . $^{7}$ Specifically, within Africa, $13-48 \%$ of women experienced physical or sexual IPV across several countries within the continent as reported in studies over the previous decades. $3,7,8$

Annual cost of IPV against women in the United Kingdom was about $£ 22.9$ billion in $2001^{9}$ and $\ell \mid 5.7$ billion in $2008 .{ }^{10}$ In United States (U.S.) IPV cost about $\$ 8$ billion in 2003. " There are no reliably documented global, regional or country level cost of IPV for Africa. Despite widespread IPV, women remain with their abusive partners - as a protective mechanism for themselves and their children because of fear of reprisal; financial dependence on partner; anxiety over children for those with children; nonexistence of social support; societal stigma related to divorce and losing custody of children as well as expectation of partner changing. ${ }^{2}$

Risk factors associated with IPV include intrapersonal factors - including (a) women's low educational attainment, adverse childhood experience of physical and/or sexual abuse, social acceptance of violence, and past exposure to other types of abuse; ${ }^{4,6,12}$ (b) partner characteristics: partner's young age, low educational attainment, adverse childhood experience of violence, deleterious drug and alcohol use, personality disorders, social acceptance of violence, and past history of IPV., ${ }^{4}$ IPV risk factors also include interpersonal risks which comprise of relationship discontent and conflicts, male dominating relationship, financial stress, polygamous relationship, and higher female educational attainment. ${ }^{4-6,13}$ There are also community-related and societal factors which comprise of poverty, social gender norms/ roles, low female socioeconomic status, weak marital IPV-related legal sanctions, disparaging marriage and divorce laws, weak or nonexistent communityrelated IPV sanctions, social acceptance of IPV as conflict resolution measure, and societal civil instability. ${ }^{4,6}$

Consequences of IPV range from immediate to short and long-term impact on physical, mental, sexual and reproductive health as well as demise of the victim. ' Reported sexual and reproductive health consequences of IPV on women include difficulty negotiating use of contraceptives or condoms $s^{2,14,15}$ to decreased contraceptive and condom use, ${ }^{16}$ unplanned pregnancy, abortion and associated complications, sexually transmitted infections including HIV, complications of pregnancy, urinary tract infections, pelvic inflammatory disease, and sexual dysfunction. ${ }^{13,14}$

Studies on IPV and sexual and reproductive health involving African countries have been part of the broader worldwide studies ${ }^{14,16}$ or focused on only sub-Saharan ${ }^{17,18}$ or individual African countries and not the entire continent. ${ }^{19-23}$ After exhaustive literature search, we were unable to find studies comparing specifically all (combined physical, emotional, and sexual) IPV and contraceptive use within the African regions. The purpose of this study was to provide a comparative view of potential regional differences in the association between IPV as exposure and knowledge and use of contraceptives within Africa as outcomes.

\section{I.2. Objectives of the Study}

To provide a comparative analysis of potential regional differences in the association between IPV and knowledge and use of contraceptives within Africa. 


\section{Methods}

\section{I. Study Variables}

We conducted a multi-country cross-sectional study using data from the Demographic and Health Survey Program (DHS) encompassing five countries representing each of the five regions of Africa: Benin, Burundi, Egypt, Kenya, and South Africa. The DHS Program, which is funded by the U.S. Agency for International Development (USAIDS), periodically collects and distributes nationally representative data on maternal and child health, fertility, family planning, HIVIAIDS, and nutrition in developing countries. The surveys comprise three core questionnaires: household, women's, and men's surveys with standardized modules on various topics that countries might be interested in. We utilized women's survey data for this study. The main inclusion criterion for our current study was that the DHS data must be from the current decade (i.e., not more than 10 years old). For efficiency of analysis and to obtain representative results for the continent, we decided to select one country from each of the regions of the continent (i.e., Northern, Western, Central, Eastern and Southern Africa). Accordingly, we included data from Egypt (2014), Benin (2017), Burundi (2016-20I7), Kenya (20I4) and South Africa (2016) representing Northern, Western, Central, Eastern and Southern Africa respectively.

DHS survey typically takes approximately 1820 months to be completed, and the data collection process involves several steps: survey preparation and questionnaire design based on needs of hostcountry, training field staff and conducting survey through identified individual respondents, data processing and final report preparation. The woman being interviewed was selected at random among all eligible women in the household. Interview questions captured information on demographic characteristics, sexual and reproductive health, knowledge and usage of contraception, prenatal, delivery and postnatal care; vulnerability to domestic abuse, children's health and so on. Respondents' files were recoded with assigned identification numbers but names were not recorded to ensure complete anonymity. Referrals to social services and other information were provided to women in need of assistance.
Our study included all women of reproductive age (15-49 years old) from the afore-mentioned five African regions. We combined all the data from the five countries to get weighted estimates, representative of the entire African population. Women's individual standard weight variable "V005" was used as relative weight and normalized to make the procedure survey-specific. To pool data from the five countries, we de-normalized women's individual standard weight variable by dividing women's individual standard weight by sampling fraction of the specific survey. The formula for de-normalized weight variable is: Women's adjusted weight $=$ V005 $\times$ (total women aged 15-49 years in the country at the time of the survey)/(number of women aged I5-49 years interviewed in the survey). ${ }^{24}$

We created a composite variable for IPV based on questions presented to women who were selected for the domestic violence module of the survey, and who reported source of violence to be their partner and/or husband. Women who answered "yes" to any of the following items were categorized as having suffered from IPV: (I) experienced any emotional violence, (2) experienced any physical violence, and (3) experienced any sexual violence. ${ }^{25,26} \mathrm{We}$ compared women who had experienced IPV to those who did not based on various socio-demographic, sexual literacy, and partner characteristics using Pearson's chi-squared test. Variables for comparison were: age, age at start of first sex, maternal education, partner's education, marital status, knowledge of how ovulation works, knowledge and current use of contraception, place of residence, economic status based on wealth index, recent sexual activity, respondent's and partner's desire for more children, if respondent was currently working, and decisionmaker on how to spend respondent's earnings.

The outcome of interest for this study was reproductive literacy, captured in the dataset by two variables: (I) knowledge of modern methods of contraception, and (2) usage of modern methods of contraception. We identified women who had knowledge about modern methods of contraception based on survey questions bearing the following options that the woman knows; (I) no method, (2) only folkloric method, (3) only traditional method, 
and (4) modern method. For 'usage of modern methods of contraception', options available from the survey questionnaire were that the woman (I) never used, (2) used only folkloric methods, (3) used only traditional methods; and (4) used modern method. If respondent knew or used both traditional and modern methods, modern method was given priority and she was coded as knowing or using modern method. Similarly, if a woman knew or used traditional and folkloric methods, traditional method took priority. For knowledge of modern contraception, we sub-classified women without knowledge of any contraception, or knowledge of only folkloric or traditional methods as "having no knowledge of modern contraception". Similarly, for modern contraception usage variable, women who either responded that they had never used contraception or used only folkloric or traditional methods of contraception were re-categorized as "had never used modern contraception". ${ }^{25,26}$

\subsection{Statistical Analysis}

We calculated the prevalence of IPV, knowledge of and usage of modern contraceptive techniques for each of the five countries separately, and for all countries combined. Furthermore, since the prevalence of IPV was more than $10 \%$, we ran adjusted survey logbinomial regression models between (I) experience of IPV and knowledge of modern contraception, and (2) experience of IPV and usage of modern contraception. Covariates adjusted for were age, place of residence, respondent's education level and wealth index. All statistical analyses were conducted using R (version 3.5.2), RStudio (version I.I.463) and all tests of hypotheses were two-tailed with a type-I error rate set at $5 \%$.

\subsection{Ethical Approval}

As this study was performed on publicly available deidentified data, the study was approved as exempt by the Institutional Review Board (IRB) of Baylor College of Medicine, Houston, Texas.

\section{Results}

A total of 5,424,242 women were analyzed for this study. The sample comprised women from five African countries - Benin, Burundi, Egypt, Kenya, and South Africa - representing Western, Central, Northern, Eastern, and Southern African regions respectively.

\section{I. Sociodemographic Characteristics}

The prevalence of IPV was 30.8\%. In the entire combined study population, more than $50 \%$ of the women were 30 years of age or older with over half of them residing in rural areas. At the time of the interview, over $60 \%$ of the women had achieved at least secondary level of education, a proportion that was significantly greater than that of their less educated partners (Table I). The markers of financial/economic well-being were generally low with unemployment rate at more than $50 \%$, and I in 5 of the women placed within the poorest or poorer wealth index bracket. The reproductive history indicators revealed mixed findings. More than half were between 15 and 19 years old when they first started having sex and about two-thirds were married. However, less than $5 \%$ had knowledge of ovulation while almost all had knowledge of modern methods of contraception and about half did not use contraception recently. Notwithstanding, over a third of the women were sexually active in the last four weeks and more than half did not desire more children. However, over a third of women and their partners desired children (Table I).

In all the five regions of Africa, we found significant differences in women who experienced IPV compared to those who did not experience IPV across demographic, socioeconomic, and reproductive health characteristics $(p<0.000 \mathrm{I})$. These differences were more pronounced among women 25-34 years of age, and those living in rural areas. Similarly, differences in socioeconomic characteristics were more pronounced among women with lower level of education, those with partners possessing lower level of educational attainment, those currently working, those in poorer and poorest wealth index categories, and among those who usually decided alone or had their husbands/partners alone decide for them how to spend their earnings. We also observed reproductive history differences among women who were victims of IPV compared to those who were not IPV victims. 
Table I: Descriptive statistics of women I5-49 years who did not experience and who experienced intimate partner violence

\begin{tabular}{|c|c|c|c|}
\hline \multicolumn{4}{|c|}{ Intimate Partner Violence } \\
\hline \multicolumn{2}{|c|}{ No $(n=|22| \mid 229,69.2 \%)$} & \multicolumn{2}{|c|}{ Yes $(n=5424242,30.8 \%)$} \\
\hline Variables & $\%$ & $\%$ & p-value \\
\hline Age & & & $<0.0001$ \\
\hline $15-19$ years & 3.8 & 3.0 & \\
\hline $20-24$ years & 15.6 & 15.1 & \\
\hline $25-29$ years & 20.7 & 22.1 & \\
\hline $30-34$ years & 19.4 & 20.2 & \\
\hline $35-39$ years & 16.1 & 16.3 & \\
\hline $40-44$ years & 12.7 & 12.8 & \\
\hline $45-49$ years & 11.7 & 10.5 & \\
\hline Residence & & & $<0.0001$ \\
\hline Urban & 50.6 & 42.1 & \\
\hline Rural & 49.4 & 57.9 & \\
\hline Education & & & $<0.0001$ \\
\hline No education & 14.9 & 22.8 & \\
\hline Primary & 13.4 & 22.9 & \\
\hline Secondary & 57.2 & 47.2 & \\
\hline Higher & 14.5 & 7.2 & \\
\hline Partner's education & & & $<0.0001$ \\
\hline No education & 10.5 & 16.3 & \\
\hline Primary & 13.7 & 21.5 & \\
\hline Secondary & 40.3 & 37.2 & \\
\hline Higher & 13.2 & 6.4 & \\
\hline Don't know & 0.4 & 0.5 & \\
\hline NA & 22.0 & 18.2 & \\
\hline Respondent currently working & & & $<0.0001$ \\
\hline No & 62.8 & 55.7 & \\
\hline Yes & 37.1 & 44.3 & \\
\hline Wealth Index & & & $<0.0001$ \\
\hline Poorest & 16.5 & 21.2 & \\
\hline Poorer & 20.1 & 22.5 & \\
\hline Middle & 22.0 & 21.5 & \\
\hline Richer & 20.8 & 20.4 & \\
\hline Richest & 20.6 & 14.4 & \\
\hline Person who usually decides how to & & & $<0.0001$ \\
\hline Respondent alone & 8.0 & 12.2 & \\
\hline Respondent and husband/partner & 14.1 & 11.7 & \\
\hline Husband/partner alone & 1.5 & 2.2 & \\
\hline Someone else & 0.0 & 0.0 & \\
\hline Age at start of first sex & & & $<0.0001$ \\
\hline Never had sex & 0.6 & 0.1 & \\
\hline
\end{tabular}


Table I: (Continued)

\begin{tabular}{|c|c|c|c|}
\hline \multicolumn{4}{|c|}{ Intimate Partner Violence } \\
\hline \multicolumn{2}{|l|}{ No $(n=|22| \mid 229,69.2 \%)$} & \multicolumn{2}{|c|}{ Yes $(n=5424242,30.8 \%)$} \\
\hline Variables & $\%$ & $\%$ & p-value \\
\hline$<10$ years & 0.5 & 0.6 & \\
\hline 10-14 years & 5.5 & 9.3 & \\
\hline $15-19$ years & 57.7 & 60.4 & \\
\hline $20-24$ years & 26.6 & 22.4 & \\
\hline $25-29$ years & 5.9 & 4.1 & \\
\hline$\geq 30$ years & 3.3 & 3.0 & \\
\hline Marital Status & & & $<0.0001$ \\
\hline Never in union & 18.2 & 11.9 & \\
\hline Married & 65.6 & 64.2 & \\
\hline Living with partner & 10.4 & 12.0 & \\
\hline Widowed & 3.2 & 3.5 & \\
\hline Divorced & $\mathrm{I} . \mathrm{I}$ & 2.9 & \\
\hline No longer living together/separated & 1.5 & 5.4 & \\
\hline Ovulation knowledge & & & $<0.0001$ \\
\hline No & 5.4 & 13.2 & \\
\hline Yes & 1.7 & 2.4 & \\
\hline Knowledge of contraception & & & $<0.0001$ \\
\hline Knows no method & 0.3 & 0.3 & \\
\hline Knows only folkloric method & 0.0 & 0.0 & \\
\hline Knows only traditional method & 0.0 & 0.0 & \\
\hline Knows modern method & 99.7 & 99.7 & \\
\hline Current use of contraception & & & $<0.0001$ \\
\hline Never used & 47.7 & 50.6 & \\
\hline Used folkloric method & 0.0 & 0.0 & \\
\hline Used traditional method & 1.5 & 1.8 & \\
\hline Used modern method & 50.8 & 47.6 & \\
\hline Recent sexual activity & & & $<0.0001$ \\
\hline Never had sex & 0.6 & 0.1 & \\
\hline Active in last 4 weeks & 38.9 & 39.2 & \\
\hline Not active in last 4 weeks - postpartum abstinence & 3.1 & 3.3 & \\
\hline Not active in last 4 weeks - not postpartum abstinence & 17.2 & 18.5 & \\
\hline Desire for more children & & & $<0.0001$ \\
\hline Wants within 2 years & 15.1 & 14.8 & \\
\hline Wants after $2+$ years & I8. & 18.7 & \\
\hline Wants, unsure timing & 6.1 & 4.0 & \\
\hline Undecided & 4.7 & 3.5 & \\
\hline Wants no more & 51.1 & 54.0 & \\
\hline Sterilized (respondent or partner) & 2.9 & 2.8 & \\
\hline Declared infecund & 1.8 & 2.1 & \\
\hline Never had sex & 0.0 & 0.0 & \\
\hline
\end{tabular}


Table I: (Continued)

\begin{tabular}{|c|c|c|c|}
\hline \multicolumn{4}{|c|}{ Intimate Partner Violence } \\
\hline \multicolumn{2}{|c|}{ No $(n=|22| \mid 229,69.2 \%)$} & \multicolumn{2}{|c|}{ Yes $(n=5424242,30.8 \%)$} \\
\hline Variables & $\%$ & $\%$ & p-value \\
\hline Husband's desire for children & & & $<0.0001$ \\
\hline Both want same & 46.0 & 37.0 & \\
\hline Husband wants more & 15.6 & 20.6 & \\
\hline Husband wants fewer & 3.8 & 6.6 & \\
\hline Don't know & 8.1 & 9.8 & \\
\hline
\end{tabular}

Sum of some variable percentages did not attain $100 \%$ because missing values were not included.

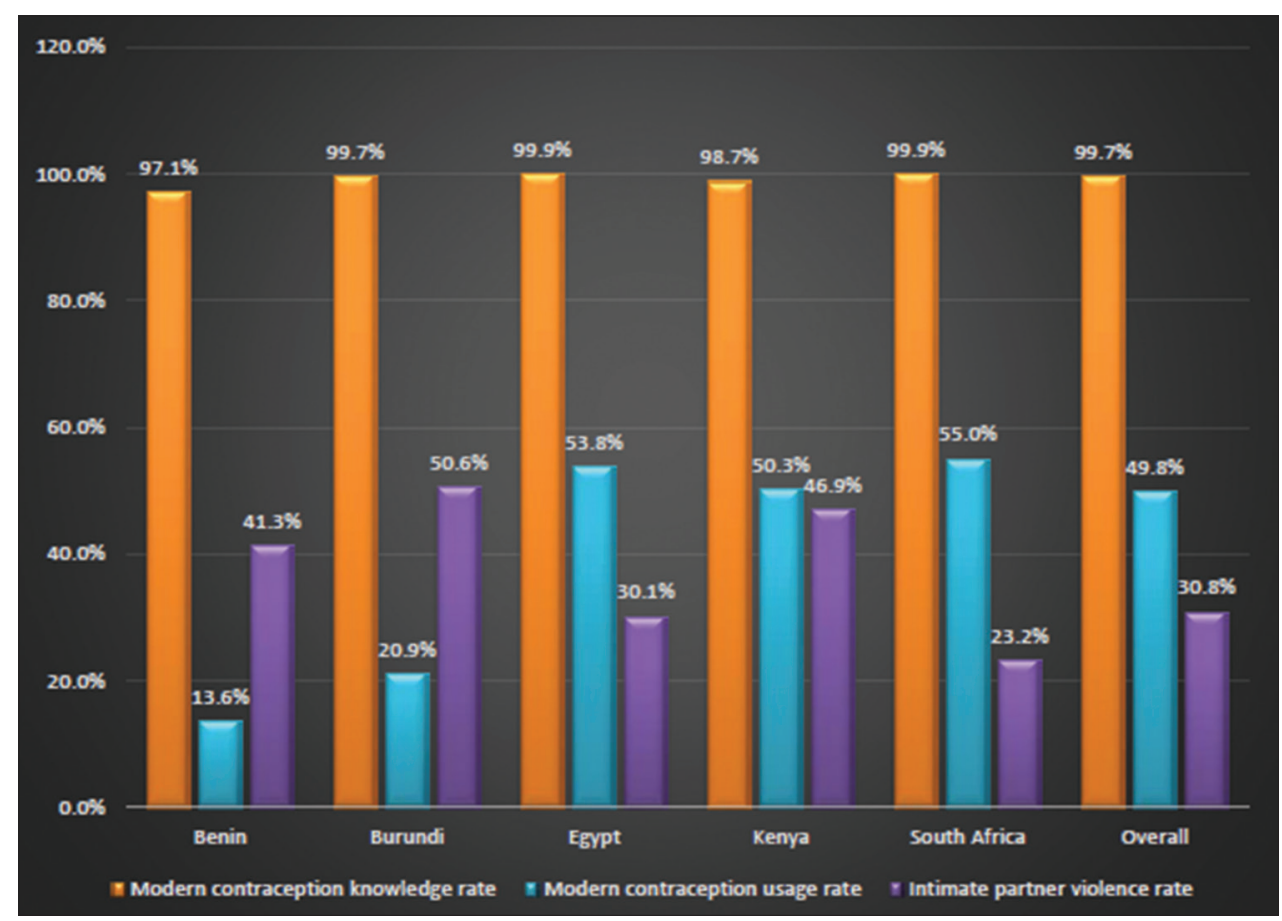

Figure I: Overall and regional proportions of intimate partner violence, knowledge and usage of modern contraception in Africa

These differences were manifested more in women whose age at first sex was between 10 and 19 years of age as well as in those living with a partner. Additionally, we found variations among women without knowledge of ovulation, those who had never used contraception, among women who did not desire more children, and among women whose partners desired children. There were differences observed with other variables but these variations were not as pronounced as those described above (Table I).
Figure I shows overall and regional prevalences of IPV, modern contraception knowledge, and usage of modern contraception in Africa.About I in 3 women in Africa was a victim of IPV with twice as many women possessing knowledge of modern contraception as those who used modern contraception. The figure illustrated notable regional differences. In western Africa, over $40 \%$ of women experienced IPV with seven times more women having knowledge of modern contraception than those who used modern contraception. Similarly, in central Africa, 
slightly more than $50 \%$ of women were IPV victims with about five times as many women possessing knowledge of modern contraception as those who used modern contraception. In the northern, eastern, and southern regions the prevalence of IPV was less than $50 \%$ and the ratio of women who were knowledgeable about modern contraception to those who used modern contraception was only about 2 to I.

\subsection{IPV Exposure and Knowledge of Modern Contraception}

Adjusted prevalence ratios capturing the association between IPV exposure and knowledge of modern contraception only are displayed in Table 2 . The level of knowledge of contraception was $84 \%$ greater among African women who were victims of IPV as compared to their counterparts who were not $(p<0.000 \mathrm{I})$. In addition, the following demographic characteristics were predictive of modern contraception knowledge independent of IPV status: I) Age - women in the 40-44 years age group were about three time more likely than the 20-24 year olds to possess this knowledge. 2) Residence women who resided in rural areas were $73 \%$ more likely to have modern contraception knowledge. Women with secondary and lower educational attainment and those in the poorest wealth index category were, however, less likely to have modern contraception knowledge regardless of IPV status (Table 2).

\subsection{IPV Exposure and Usage of Modern Contraception}

Table 3 summarizes the adjusted prevalence ratios for IPV and usage of modern contraception only. IPV was not associated with usage of modern contraception. Demographic characteristic predictive of modern contraception usage regardless of IPV status included: residence - women resident in rural areas were $21 \%$ more likely to use modern contraception. On the other hand, compared to adolescent women, those 20-49 years of age were less likely to use modern contraception regardless of IPV status (Table 3). Similarly, women with educational attainment lower than secondary level were more likely to use modern contraception. However, the relationship between
Table 2: Adjusted weighted survey log-binomial regression model for intimate partner violence and modern contraception knowledge

\begin{tabular}{|c|c|c|}
\hline & Adjusted PR & p-value \\
\hline \multicolumn{3}{|c|}{ Intimate partner violence } \\
\hline No & reference & \\
\hline Yes & I.84(1.22-2.07) & $<0.0001$ \\
\hline \multicolumn{3}{|l|}{ Age (years) } \\
\hline $15-19$ & reference & \\
\hline $20-24$ & $3.66(1.75-7.66)$ & $<0.0001$ \\
\hline $25-29$ & $5.60(2.75-1 \mid .37)$ & $<0.0001$ \\
\hline $30-34$ & $8.43(3.76-18.93)$ & $<0.0001$ \\
\hline $35-39$ & $6.42(2.36-17.46)$ & $<0.0001$ \\
\hline $40-44$ & $10.10(4.40-23.20)$ & $<0.0001$ \\
\hline $45-49$ & $8.88(3.69-21.38)$ & $<0.0001$ \\
\hline \multicolumn{3}{|l|}{ Residence } \\
\hline Urban & reference & \\
\hline Rural & I.73(1.04-2.89) & 0.04 \\
\hline \multicolumn{3}{|l|}{ Education } \\
\hline Higher & reference & \\
\hline No education & $0.00(0.00-0.01)$ & $<0.0001$ \\
\hline Primary & $0.01(0.00-0.06)$ & $<0.0001$ \\
\hline Secondary & $0.04(0.00-0.40)$ & $<0.0001$ \\
\hline \multicolumn{3}{|l|}{ Wealth index } \\
\hline Richest & reference & \\
\hline Poorest & $0.20(0.06-0.72)$ & 0.01 \\
\hline Poorer & $0.57(0.15-2.16)$ & 0.41 \\
\hline Middle & $0.58(0.12-2.82)$ & 0.50 \\
\hline Richer & I.I7(0.3|-4.42) & 0.81 \\
\hline
\end{tabular}

wealth index and poverty level revealed that women in the richest wealth index category were the most likely group to use modern contraception when compared to the other economic strata.

\section{Discussion}

\section{I. Discussion}

In this study, the overall prevalence of intimate partner violence (IPV) against women in Africa was approximately $31 \%$. Similar to other studies, we observed variations in the prevalence of IPV in Africa. ${ }^{1,2,4,6,7,12,14,17}$ To our knowledge, however, ours is the first to research IPV across all five African regions. The prevalence of IPV varies between and within study sites, ${ }^{1-8}$ based on type and number 
Table 3:Adjusted weighted survey log-binomial regression model for intimate partner violence and modern contraception usage

\begin{tabular}{|c|c|c|}
\hline & Adjusted PR & p-value \\
\hline \multicolumn{3}{|c|}{ Intimate partner violence } \\
\hline No & reference & \\
\hline Yes & $1.06(0.97-1.16)$ & 0.21 \\
\hline \multicolumn{3}{|l|}{ Age (years) } \\
\hline $15-19$ & reference & \\
\hline $20-24$ & $0.58(0.44-0.75)$ & $<0.0001$ \\
\hline $25-29$ & $0.44(0.34-0.57)$ & $<0.0001$ \\
\hline $30-34$ & $0.38(0.29-0.49)$ & $<0.0001$ \\
\hline $35-39$ & $0.37(0.28-0.48)$ & $<0.0001$ \\
\hline $40-44$ & $0.40(0.30-0.52)$ & $<0.0001$ \\
\hline $45-49$ & $0.68(0.52-0.90)$ & $<0.0001$ \\
\hline \multicolumn{3}{|l|}{ Residence } \\
\hline Urban & reference & \\
\hline Rural & $1.21(1.08-1.36)$ & $<0.0001$ \\
\hline \multicolumn{3}{|l|}{ Education } \\
\hline Higher & reference & \\
\hline No education & $2.10(1.78-2.47)$ & $<0.0001$ \\
\hline Primary & $1.49(1.27-1.74)$ & $<0.0001$ \\
\hline Secondary & $1.06(0.91-1.23)$ & 0.46 \\
\hline \multicolumn{3}{|l|}{ Wealth Index } \\
\hline Richest & reference & \\
\hline Poorest & $0.8 \mathrm{I}(0.67-0.97)$ & 0.02 \\
\hline Poorer & $0.80(0.67-0.95)$ & 0.01 \\
\hline Middle & $0.80(0.68-0.94)$ & 0.01 \\
\hline Richer & $0.83(0.73-0.96)$ & 0.01 \\
\hline
\end{tabular}

of IPV studied, ${ }^{1-8}$ as well as methodological designs. ${ }^{4,6,12}$ Previously reported life time ${ }^{1,7}$ and annual prevalence $4,6,7,12$ of IPV might have been underestimated due to lower reporting rates, fear of stigma, victimization, retaliation, inadequate or lack of healthcare provider knowledge and training associated with IPV. ${ }^{1,6,7,16,27,28}$ Our study was not an exception. However, the multi-country nature of our analysis across all five African regions and multiple types of IPV studied make our result more generalizable.

Knowledge of modern contraception was high among IPV victims in all the five African regions. However, usage was lower compared to knowledge of modern contraception across all regions. This was more pronounced in western and central Africa. IPV victims may be motivated and empowered to seek knowledge and use modern contraception as protective mechanisms against the consequences of IPV. This was substantiated by our finding of IPV victims not wanting or waiting two or more years for more children compared to non-IPV victims. Demographic, socioeconomic, and reproductive history characteristics of IPV victims in our study were consistent with prior reports and included: young age, low maternal and partner educational attainment, unemployment, low level of income/ poverty, exposure to sex at an early age, and marriage. ${ }^{1,3,4,6,12,14,19}$ To our knowledge, ours is the first study to delineate new characteristics associated with IPV victims not reported in prior literature. This included features such as decisionmaking regarding how women spend their earnings. In addition, reproductive history characteristics like poor ovulation knowledge, current sexual activity, and desire for children were novel areas that could be candidates for targeted intervention.

\subsection{Limitations}

This was a cross-sectional study and we were therefore, unable to establish temporality between IPV against women and knowledge or usage of contraception. Hence, it is difficult to establish a cause-effect relationship in our findings. Since the outcomes of the study were self-reported, our results could have been impacted by recall as well as misclassification biases. Further research is needed to understand the significance of existing and newly identified characteristics associated with IPV against women. More work is required to determine the impact of these characteristics on specific policies, resources, and interventions for preventing and managing IPV against women.

\section{Conclusion and Global Health Implications}

This study provides previously unavailable information about the association between IPV victims, knowledge and usage of contraception in all African regions. Despite regional variabilities, the study reported characteristics predictive of IPV against women, knowledge and usage of 
contraception. These characteristics have significant global and regional implications especially, regarding policy development, decision-making, resource allocation, prevention and management of IPV against women.

\section{Compliance with Ethical Standards}

Conflicts of Interest: All authors of this study have no conflict of interest to declare. Financial Disclosure: All authors of this study have no financial disclosure to make. Funding/Support: This study was non-funded. Ethics Approval: This study was approved as exempt by the Institutional Review Board (IRB) of Baylor College of Medicine, Houston, Texas.

\section{Key Messages}

- Regional differences exist among women who experienced IPV in Africa.

- Usage of modern contraception was lower compared to knowledge of modern contraception among IPV victims across all regions in Africa.

- Novel factors such as "decision-making regarding how women spend their earnings", “ovulation knowledge", "current sexual activity", and "desire for children", and their associations with IPV require further studies.

\section{References}

I. World Health Organization. Understanding and Addressing Violence against Women: Intimate Partner Violence. No. WHO/RHR/I2.36. World Health Organization; 2012.

2. Heise L, Ellsberg M, Gottemoeller M. Ending violence against women. Popul Rep L. 1999; I I: I-43.

3. World Health Organization (WHO). Intimate partner violence: Facts. 2002. http://www.who.int/ violence_injury_prevention/violence/world_report/ factsheets/en/ipvfacts.pdf.Accessed May 19, 2019.

4. Heise L, Garcia-Moreno C. Violence by intimate partners. In: World report on violence and health. Geneva, World Health Organization; 2002:87-121.

5. Garcia-Moreno C, Jansen HA, Ellsberg M, et al.WHO multi-country study on women's health and domestic violence against women: initial results on prevalence, health outcomes and women's responses. Geneva: World Health Organization; 2005;204: I - 18.

6. World Health Organization. Preventing intimate partner and sexual violence against women: taking action and generating evidence. 20/0. http:// www.who.int/reproductivehealth/publications/ violence/978924I564007/en/. Accessed May 19, 2019.

7. Garcia-Moreno C, Jansen HA, Ellsberg M, et al. Prevalence of intimate partner violence: findings from the WHO multi-country study on women's health and domestic violence. The Lancet. 2006;368(9543): 1260-1269.

8. Kishor S, Johnson K. Profiling domestic violence: a multi-country study. Calverton, Maryland, ORC Macro, MEASURE DHS+; 2004:I 18.

9. WalbyS.The costofdomesticviolence.London:Women and Equality Unit (DTI); 2004. Available at: http:// openaccess.city.ac.uk/2I68I/I/The20Cost20of20 Domestic20Violence.pdf.Accessed May 19, 2019.

10. Walby S. The cost of domestic violence: update 2009. Lancaster: Lancaster University; 2009. Available at: http://openaccess.city.ac.uk/2168I/l/ The20Cost20 of 20Domestic20Violence.pdf. Accessed May 19, 2019.

II. Max W, Rice DP, Finkelstein E, et al. The economic toll of intimate partner violence against women in the United States. Violence Vict. 2004; 19(3):259-272.

12. Abramsky T, Watts CH, Garcia-Moreno C, et al. What factors are associated with recent intimate partner violence? Findings from the WHO multicountry study on women's health and domestic violence. BMC Public Health. 20 I I; I I ( I): 109.

13. Campbell JC. Health consequences of intimate partner violence. The Lancet. 2002;359(93 I4):13311336.

14. Maxwell L, Nandi A, Benedetti A, et al. Intimate partner violence and pregnancy spacing: results from a meta-analysis of individual participant timeto-event data from 29 low-and-middle-income countries. BMJ Glob Health. 2018;3(I):e000304.

15. Bergmann JN, Stockman JK. How does intimate partner violence affect condom and oral contraceptive use in the United States? A systematic review of the literature. Contraception. 2015;9I(6):438-455.

16. Maxwell L, Devries K, Zionts D, et al. Estimating the 
effect of intimate partner violence on women's use of contraception: a systematic review and metaanalysis. PloS One. 20 I5; I0(2):e0 I I 8234.

17. Alio AP, Daley EM, Nana PN, Duan J, Salihu HM. Intimate partner violence and contraception use among women in Sub-Saharan Africa. Int J Gynecol Obstet. 2009;107(I):35-38.

18. Yaya S, Bishwajit G. Regional prevalence, patterns and correlates of sexual coercion among women in Sub-Saharan Africa: a multi-country populationbased study. Int J Sex Health. 20 I8;30(2):224-235.

19. Alio AP, Nana PN, Salihu HM. Spousal violence and potentially preventable single and recurrent spontaneous fetal loss in an African setting: crosssectional study. The Lancet. 2009;373(9660):3 I8-324.

20. Alio AP, Salihu HM, Nana PN, et al. Association between intimate partner violence and induced abortion in Cameroon. Int J Gynecol Obstet. 20I I; I I 2(2):83-87.

21. Ameh N, Kene TS, Onuh SO, et al. Burden of domestic violence amongst infertile women attending infertility clinics in Nigeria. Niger J Med. 2007;16(4):375-377.

22. Abuya BA, Onsomu EO, Moore D, et al. Association between education and domestic violence among women being offered an HIV test in urban and rural areas in Kenya.J Interpers Violence. 20I 2;27(I0):20222038.

23. Dude AM. Spousal intimate partner violence is associated with HIV and other STls among married Rwandan women. AIDS Behav. 20 I I; I5(I):I42-I52.

24. DHS Program User Forum. USAID. 20I3. Available at: https://userforum.dhsprogram.com/index.php? $\mathrm{t}=\mathrm{msg \& goto}=9556 \&$. Accessed May 27, 2019.

25. Dongarwar D, Salihu HM. Influence of sexual and reproductive health literacy on single and recurrent adolescent pregnancy in Latin America. J Pediatr Adolesc Gynecol. 2019. doi: I0.1016/j.jpag.2019.06.003.

26. Khan SF, Dongarwar D,Aliyu MH, et al. Multicountry analysis of pregnancy termination and intimate partner violence in Latin America using Demographic and Health Survey data. Int J Gynecol Obstet. 20 I 9. doi: 10.1002/ijgo. 12876.

27. World Health Organization. Responding to intimate partner violence and sexual violence against women: WHO clinical and policy guidelines. Geneva, World Health Organization; 20I3.

28. Feder GS, Hutson M, Ramsay J, et al. Women exposed to intimate partner violence: expectations and experiences when they encounter health care professionals: a meta-analysis of qualitative studies. Arch Intern Med. 2006; I66(I):22-37. 